\title{
Hazır Giyim İşletmelerinde Üretim Hattında Kullanılan Online Üretim Takip Sistemleri
}

\author{
Serkan Boz ${ }^{1 *}$, Derya Tama Birkocak ${ }^{2}$ \\ ${ }^{1 *}$ Ege Üniversitesi, Moda ve Tasarım Yüksekokulu, Moda Tasarımı Bölümü, İzmir, Türkiye, (ORCID: 0000-0002-2989-1105), serkan.boz@ege.edu.tr \\ ${ }^{2}$ Ege Üniversitesi, Mühendislik Fakültesi, Tekstil Mühendisliği Bölümü, İzmir, Türkiye (ORCID: 0000-0002-2720-2484), derya.tama@ege.edu.tr
}

(International Conference on Design, Research and Development (RDCONF) 2021 - 15-18 December 2021)

(DOI: 10.31590/ejosat.1038533)

ATIF/REFERENCE: Boz, S. \& Tama Birkocak, D. (2021). Hazır Giyim İşletmelerinde Üretim Hattında Kullanılan Online Üretim Takip Sistemleri. Avrupa Bilim ve Teknoloji Dergisi, (32), 741-747.

\section{Öz}

Konfeksiyon sektöründe faaliyet gösteren firmalar, uluslararası pazarlardaki rekabet güçlerini koruyabilmek için daha kaliteli ürünü daha hızlı ve daha düşük maliyetle üretmek ve sevk etmek zorundadırlar. Bu kapsamda ön plana çıkan verimlilik kavramının öneminin giderek artması verimlilik ölçümüne de gereken önemin verilmesini sağlamıştır. Konfeksiyon işletmelerinde verimlilik ölçümünde, iş süresi ve iş sayılarının, zaman ve iş etütlerinin gerçekleştirilmesiyle tespit edildiği görülmektedir.

Bu çalışmada performansın sürekli ölçümü için işçinin yaptığı iş miktarını kaydeden makineye bağlı online üretim takip sistemlerinin çalışma prensibi ve bu sistemin avantajları örnek bir sistem üzerinden anlatılmaktadır. Bu örnek sistemin yüklü olduğu bir hazır giyim işletmesinde üretime yeni giren önden bağcıklı, uzun kollu ve ön ortası büzgü detaylı bir bolero modeline ait veriler, siparişin tamamlanma süresi olan 8 gün boyunca kayıt altına alınmıştır. Modele ait operasyon ve model bazında verimlilik değerleri ile üretim süresince yaşanan dakika bazında duruş verileri sunularak değerlendirilmiştir.

Anahtar Kelimeler: Konfeksiyon, verimlilik, üretim takibi, online üretim takip sistemi.

\section{Online Production Monitoring Systems Used in Production Lines in Apparel Industry}

\begin{abstract}
To maintain their competitiveness in international markets, the apparel manufacturers must produce and ship the products faster and at lower cost with higher quality. In this context, the increasing importance of the concept of efficiency, which comes to the forefront, has provided the necessary importance to be given to the measurement of productivity. It is seen that, in the productivity measurement of apparel manufacturing process, the manufacturers use "work study" and "time study" to determine work time and work numbers. In this study, the working principle of online production monitoring systems connected to the machine, which records the amount of work done by the operator for continuous measurement of performance, and the advantages of this system are explained through a sample system. The data of a bolero model with a souffle collar, long sleeves and a shirring detail in the middle of the front, which has just entered production in an apparel company, were recorded with this online production monitoring system for 8 days. The operational and model-based efficiency values of the model and the non-productive time data during the production were presented and evaluated.
\end{abstract}

Keywords: Apparel, productivity, production monitoring, online production monitoring system.

\footnotetext{
*Sorumlu Yazar: serkan.boz@ege.edu.tr
} 


\section{Giriş}

Günümüz rekabet koşulları, birçok sektörde karlılığın sınırlarını oldukça aşağıya çekmiştir. Böyle bir ortamda, dinamik bir yapıya sahip olan tekstil ve hazır giyim sanayiinde faaliyet gösteren firmaların karlılıklarını koruyabilmelerinin öncelikli yolu verimlilikten geçmektedir.

Verimlilik genel olarak; üretim süreci sonunda elde edilenlerle, bu sonucu elde etmek için üretim sürecine alınanlar, bir başka deyişle çıktılarla girdiler arasındaki bir katsayı, bir orandır [1]. Peter Drucker'a göre verimlilik en az çaba ile en çok çıktıyı verebilecek bütün üretim kaynakları arasındaki dengedir $[2,3]$. İşletmede verimlilik, etkililik ve etkenlik analizine yardımcı olmak amacıyla ölçülür. Verimlilik, karlar ve fiyatlar arasında bir denge kurulabilmesi için verimlilik ölçüm sistemi, yönetim bilgi sisteminin ayrılmaz bir parçası olmak zorundadır [3]. Üretim sürecinin verimini belirleyen üç temel etken bulunmaktadır; süreç içerisindeki emeğin nitelik düzeyi, süreç için harcanan zaman, süreçte kullanılan teknoloji [4]. Günümüzde işletmeler, üretim süreçlerini daha etkin kılmak ve maliyetleri düşürmek için de üretim sistemlerinde teknolojik yenilenmeye gitmektedirler [5].

Bilgisayar ve iletişim teknolojilerindeki gelişmeler maliyet, zaman, kalite ve hizmet konularında işletme faaliyetlerini sürekli olarak etkilemekte ve değiştirmektedir. Özellikle bilişim teknolojilerindeki gelişmeler, işletme yapısında köklü değişikliklere neden olmakta ve işletmelere, yeni pazarlara girmede, ürünlerini ve hizmetlerini sunmada, süreçlerinin verimliliğini artırmada, müşteri kazanımında ve müşteri sadakatinin sağlanmasında yeni yollar sunmaktadır [6]. Bu nedenle günümüzde üretim işletmeleri maliyet muhasebesi ve üretim takip sistemlerini oluşturma noktasında bilgi sistemlerine önemli yatırımlar yapmaktadırlar. Üretim süreçlerini daha etkin takip altına alabilmek ve maliyetlerini daha doğru hesaplayabilmek amaciyla bu sistemlere ciddi zaman ve para harcayan işletmelerin bazen umduklarını bulamadıkları da bir gerçektir. Çünkü özellikle karmaşık bir üretim yapısına sahip sektör ve işletmelerde istenilen sonuçları elde etmek ciddi bir uzmanlık ve yoğun çalışma gerektirmektedir [5].

Boorla and Howard (2016) çalışmalarında üretim performansının tahminlenebilmesi için yeni bir üretim takip modeli önermişlerdir. $\mathrm{Bu}$ yeni modelde, üretilen ürünün kalitesinin yerine son ürünün performansına öncelik vermişlerdir [7]. Prasad et al. (2016), kalem üretim işletmesinde üretim takip sistemini kullanarak üretimin verimliliğini ve ürünlerin kalitesini değerlendirmişler ve elde ettikleri verileri göz önünde bulundurarak verimliliği artıracak önerilerde bulunmuşlardır [8]. Cwikla (2014), gerçekleştirdiği çalışmada gerçek zamanlı üretim takip yönteminde sıralı üretim istasyon tekniğini incelemiştir. $\mathrm{Bu}$ şekilde modüler üretim ya da küçük üretim sistemleri ile çalışılabileceğini belirtmiştir [9]. Li et al. (2003), karmaşık bir üretim yapısına sahip ürünlerin üretimleri için yeni bir gerçek zamanlı üretim takip sistemi tasarlamışlardır ve Havacılık ve Uzay Enstitüsü'nün montaj hattında bu sistemi uygulayarak başarılı sonuçlar elde etmişlerdir [10]. Huang et al. (2016), çalışmalarında kablosuz ağ iletişimi ile veri toplama amacıyla, insan-makine etkileşimli bilgi toplayabilecekleri bir film kondansatörü üretim takip sistemi geliştirmişler. Geliştirdikleri bu sistem ERP (Enterprise Resource Planning - Kurumsal Kaynak Planlaması) sistemine otomatik olarak bağlanabilmektedir [11]. Cida ve Sağbaş (2019), metal e-ISSN: 2148-2683 sektöründe sevkiyat performansının iyileştirilmesine yönelik, RFID teknolojisinin kullanılmasıyla bir devre geliştirmişlerdir [12]. Bu sayede, sevkiyat öncesi ürün tanımlanmasında $\% 97$, sevkiyat sırasında ürün kontrolünde $\% 1$ ve ürünlerin araca yüklenmesi aşamasında $\% 92$ oranında iyileştirme gerçekleştirmişlerdir. Yapılan iyileştirmenin, proces bazında maliyete etkisi işe \%96'dır. Boz ve Arıkan (2018), çalışmalarında akıllı kumaş kontrol makinelerini incelemişler ve klasik kumaş kontrol makineleriyle karşılaştırmışlardır [13]. Teknolojinin devreye girdiği birçok alanda olduğu gibi bu makinelerin kullanımıyla da \%55-60 maliyet düşüşünün sağlandığını belirtmişlerdir. Rohman et al. (2020) çalışmalarında öncelikle 1909 tekstil işletmesiyle görüşme yaparak mevcut procesleri incelemişler, sonrasında ise hammadde verilerinin bütün departmanlar tarafından gözlemlenebileceği ve yönetilebileceği bir üretim takip sistemi geliştirerek önermişlerdir [14]. Sitepu et al. (2021), Endonezya'da şapka üreten bir işletmeye, bilgisayar tabanlı üretim takip sistemi uygulaması yapmışlar ve 4 ay boyunca hem sistemsel veri toplayarak üretimdeki değişimleri, hem de gözlemler yaparak kullanıcıların bu sistemi kabullenme seviyelerini değerlendirmişlerdir [15]. Çalışma sonucunda, bu sistemlerin, üretim sırasında karşılaşılan hataların sayılarında azalma sağladığı ve kullanımlarının başarıya ulaşmada önemli olduğu sanuçlarına varmışlardır. Trisdiyanti et al. (2020) literatürde bilgisayar destekli üretim taip sistemlerinin kullanıldığg çalışmalara sıklıkla rastlanıldığını ancak, bu çalışmaların büyük işletmelerin üretim optimizasyonunda gerçekleştirildiğini belirtmişler ve kendi çalışmalarında, bu sistemlerin küçük çaplı bir tekstil işletmesine uygulanması üzerine odaklanmışlardır [16]. Çalışmanın sonucunda, küçük ölçekli işletmede çalışan kullanıcıların bu programları kabul oranlarının \%90'a yakın olduğunu belirtmişlerdir.

Gerçekleştirilen bu çalışmada makineye bağlı üretim takip sistemleri detaylı olarak açıklanmış ve bu sistemlerin işletmeye sağladığı avantajlar hakkında bilgi verilmiştir. Ayrıca, online üretim takip sisteminin kullanılmakta olduğu bir hazır giyim işletmesinden model bazında veriler elde edilerek üretime yeni giren bir modelde verimlilik değişimine dair veriler sunulmuştur.

\section{Materyal ve Metot}

$\mathrm{Bu}$ çalışmada, Tracetech online üretim takip sistemi ve bu sistem ile elde edilen veriler materyal olarak kullanılmıştır. İzmir ilinde bulunan orta ölçekli bir hazır giyim firmasının üretim verileri, üretime yeni giren bir model bazında Tracetech online üretim takip sistemi kullanılarak kayıt altına alınmıştır.

Online üretim takip sistemleri, üretim verilerinin operatör, operasyon, ürün ve bant bazında anlık olarak alınabilmesine olanak sağlamakta ve firmaların verimlilik değerlendirmelerini anında görerek hızlı bir şekilde aksiyon almalarına firsat tanımaktadır. $\mathrm{Bu}$ sistemler hakkında detaylı bilgi, Tracetech online üretim takip sistemi üzerinden verilmiştir.

Online üretim takip sisteminde makineye bağlı dokunmatik ekranlı bir panel bulunmaktadır (Şekil 1). Operatör oturduğu makineye bağlı olan üretim takip panelini açtığında RFID kartını tanıtarak işleme başlamaktadır (Şekil 2a). Ardından sırasıyla açılan ekranlarda hangi üretim bandında çalıştı̆̆ı (Şekil 2b), hangi modelin üretiminde görev aldığı (Şekil 2c) ve hangi operasyonda görev aldı ̆̆ı (Şekil 2d) bilgileri operatör tarafından girilir. Ayrıca makineye bağlı olan panele, operasyon türü, 
üretim takip sisteminin kumanda edildiği ana bilgisayardan da tanımlanabilmektedir.

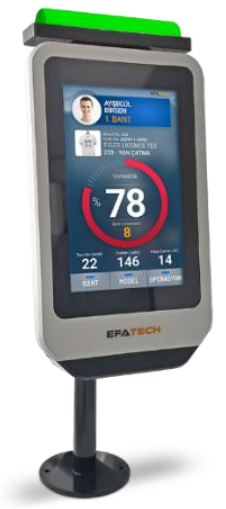

Şekil 1. Üretim takip sistemi dokunmatik paneli

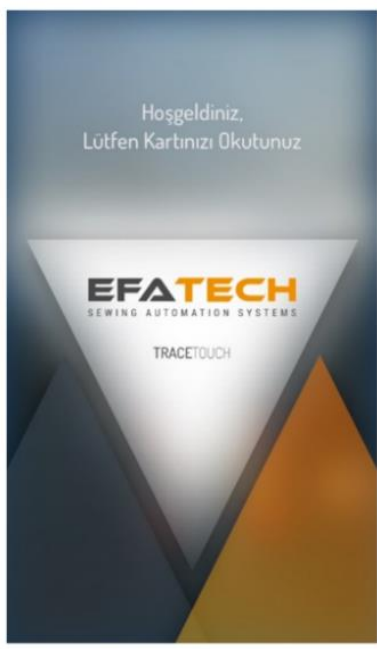

a

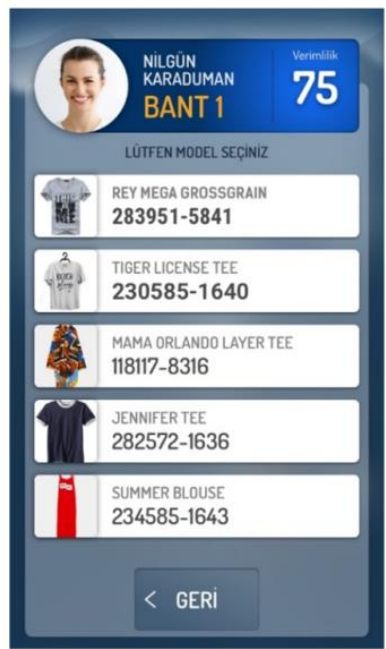

C

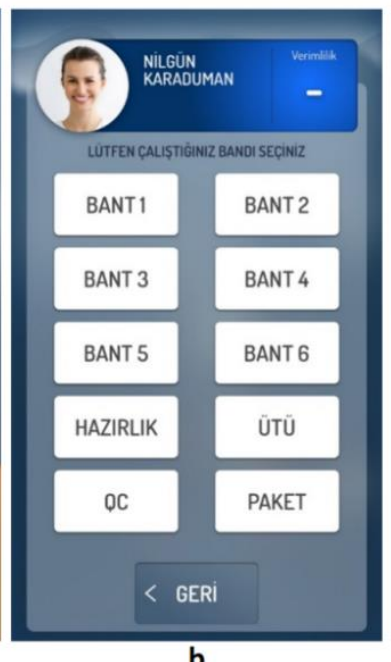

b

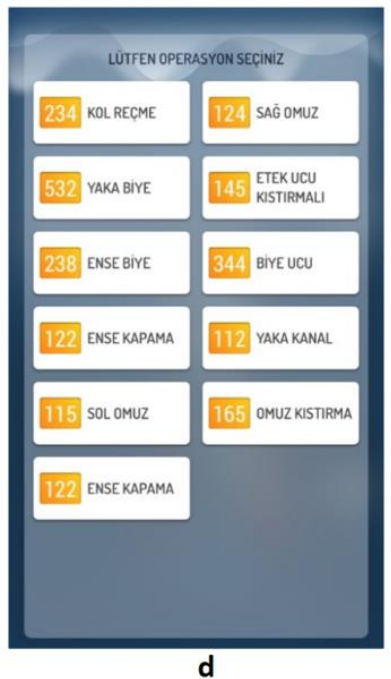

Şekil 2. a) RFID kart okutma ekranı, b) Bant seçim ekranı, c) Model seçim ekranı, d) Operasyon seçim ekranı

Tamamlanan operasyonların sayımı ise makinenin elektronik kartı aracılığıyla gerçekleştirilmektedir. Örneğin; dikiş makinelerinde operasyonların bitiminde aktive olan iplik kesiciye sinyal gittiği zaman makineye bağlı olan sayaç 1 operasyonun tamamlandığı bilgisini panele iletmektedir. İşlem bitti sinyalinin oluşmasının mümkün olmadığı, elektronik kartları olmayan ütü, kalite kontrol gibi operasyonlarda ise operatörün her işlem sonrasında bir butona basması sayesinde verimlilik kayıtlarının tutulması sağlanmaktadır. Ayrıca operatörün gerçek zamanlı olarak kendi verimliliğini takip edebilmesi de ana ekran (Şekil 3) aracılığıyla gerçekleşmektedir. $\mathrm{Bu}$ ekran aynı zamanda işçinin motivasyonunu artırmaktadır. Verimliliği düşük olan personel minimum hedef verimlilik değerini geçmek için çabalamakta, yüksek olan personel de kendisiyle yarışarak daha yüksek verimlilik değerlerine ulaşmaya çalışmaktadır.

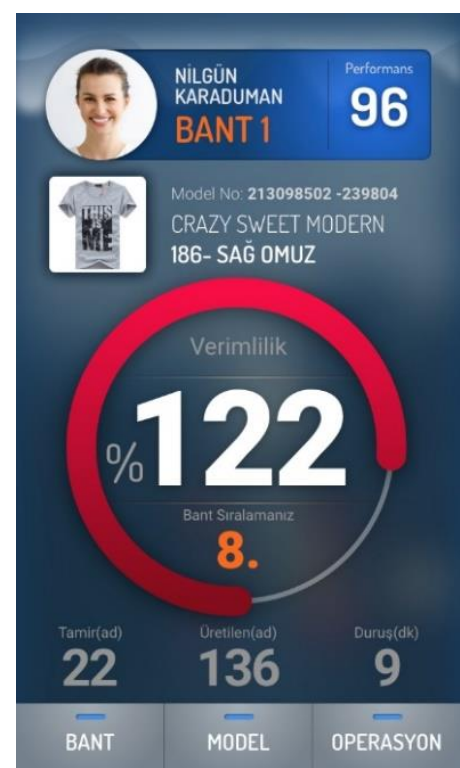

Şekil 3. Panel ana ekranı (Verimlilik takip ekranı)

Panelden ana bilgisayarlara iletim de online olarak gerçekleştirilmektedir. Online veri transferi kablolu veya kablosuz ağlarla gerçekleştirilebilir. Kablosuz ağlar, üretim bantlarında ürün değişimi nedeniyle makinelerin yerlerinin de değişmesi gerektiği zamanlarda avantaj sağlamaktadır. Ancak kablosuz a $\breve{g}$ bağdaştırıcıların mesafelerinin işletme içinde iyi ayarlanmasına ve enterferans oluşan bölgelerin ölçümlenerek minimuma indirilmesine dikkat edilmelidir.

Operatörün işlem sırasında hata yaptığg durumunda işlemi sonlandırması gerekmektedir. İşlem sonlandırıldığında panele yine "işlem bitti" sinyali ulaşacağı dolayısıyla fazla operasyon olarak kaydedilmesi söz konusudur. Hataların fazla operasyon olarak kaydedilmesi sistemin en büyük dezavantajıdır. Ancak bu durumu engellemek adına panele fazla operasyon sayısını düzeltmek için bir alt ekran daha eklenmiştir. Burada hatalı operasyonun sayımını iptal etmek için veya belirli bir sayıdan itibaren sayıma devam edebilmek için operasyon sayısı düzeltme ekranı yer almaktadır.

Kayıp zamanların detaylandırılarak tespiti ve verimlilik hesaplarına dahil edilebilmesi için de operatörün standart molalar dışında makine arızası, lavabo, toplantı ve revir gibi zorunlu hallerde işleme ara verdiği zamanları kaydetmek amacıyla duruş ekranı (Şekil 4) panele eklenmiştir. 


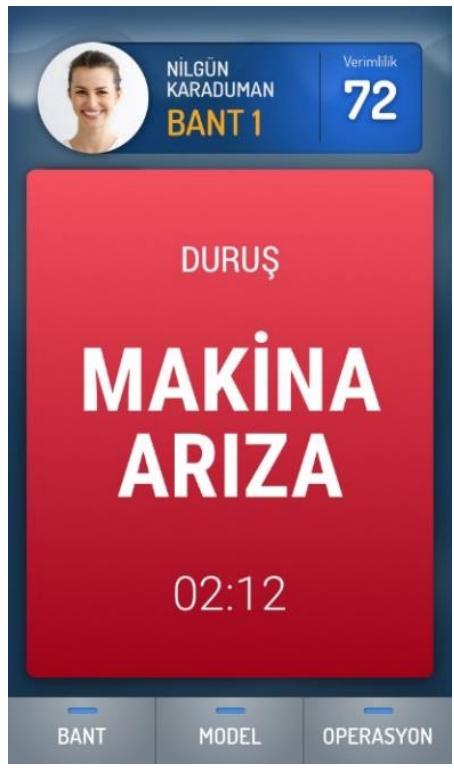

Şekil 4. Duruş ekranı

Paneldeki verilerin yanı sıra bant geneline ait verimlilik değerleri de işletme içinde belirli yerlere konumlandırılan LED ekranlara gönderilmektedir. $\mathrm{Bu}$ ekranda işletmenin genel verimlilik oranları (Şekil 5), banttaki en verimli operatörlerin listesi (Şekil 6), banttaki en düşük verimlilik oranına sahip operasyonların listesi (Şekil 7) ve ara stok (yı̆̆ın) oluşan operasyonların listesi (Şekil 8) bir döngü içinde yansıtılmaktadır.

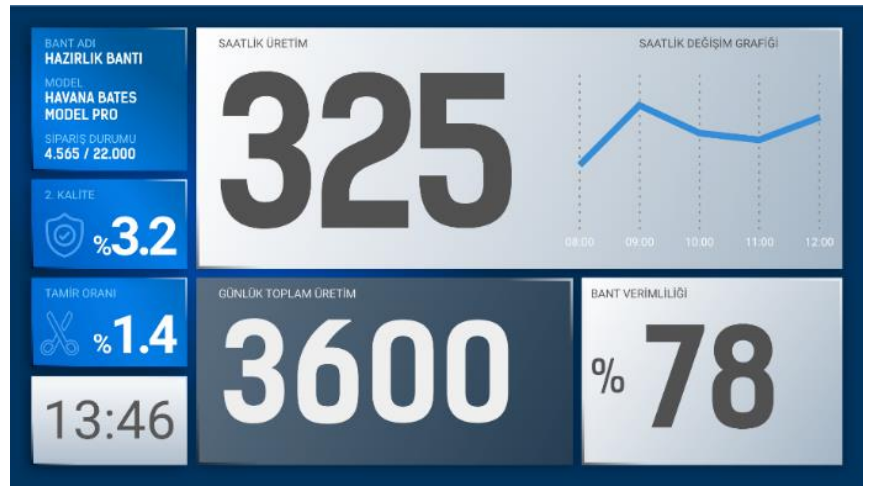

Şekil 5. Genel verimlilik oranları LED ekran görüntüsü

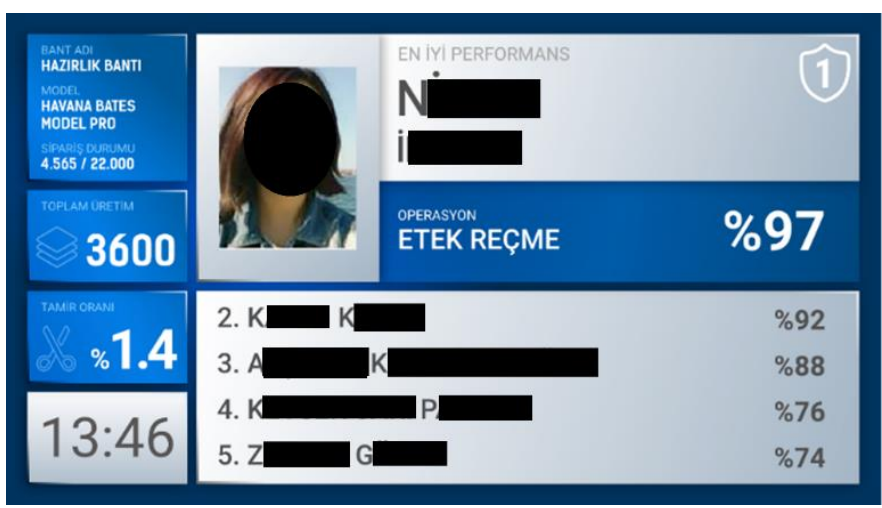

Şekil 6. En verimli operatörler listesi LED ekran görüntüsü

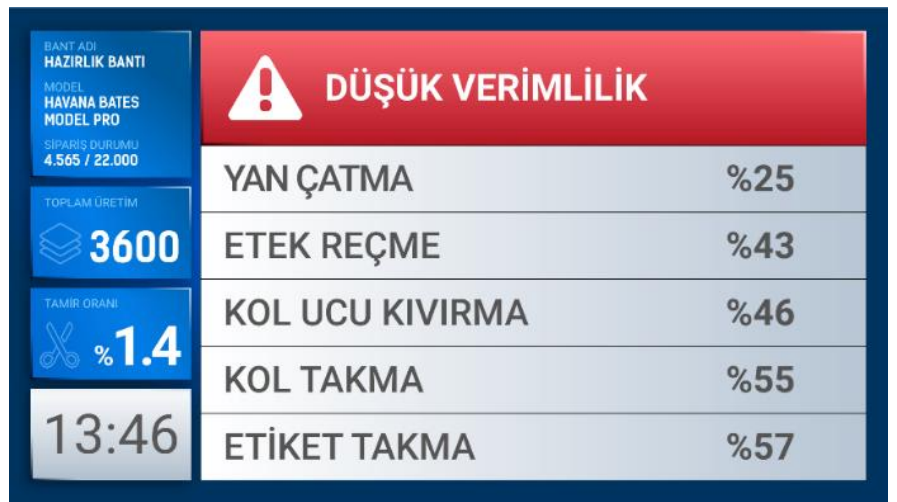

Şekil 7. En düşük verimlilik oranına sahip operasyonların LED ekran görüntüsü

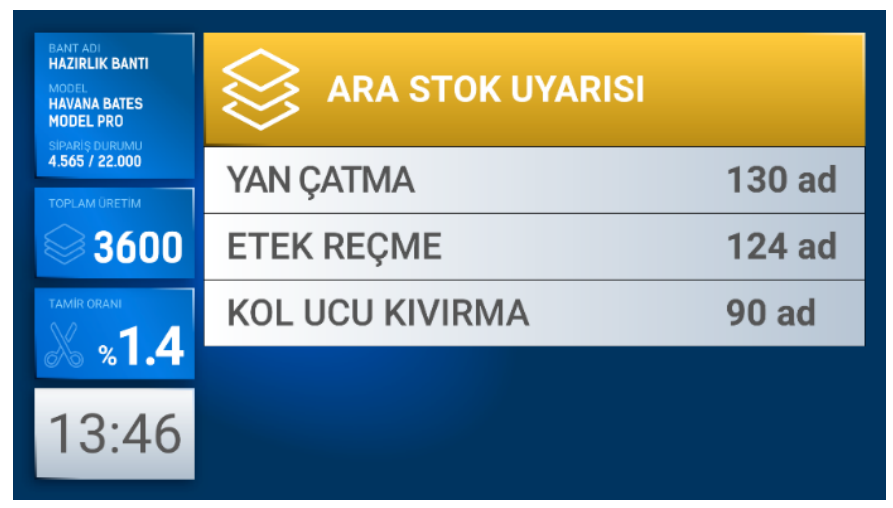

Şekil 8. Ara stok oluşan operasyonların LED ekran görüntüsü

Aynı zamanda, bu sistem sayesinde elde edilen iş ve zaman verileri kullanılarak, geliştirilen yazılım vasıtasıyla anlık verimlilik grafikleri oluşturabilmektedir. Operatörlerin, bandın ve işletmenin anlık, günlük, haftalık, aylık ve yıllık verimlilik grafiklerini elde etmek ve bu grafiklerin üzerinde analizler yapmak mümkün olmaktadır.

\section{Araştırma Sonuçları ve Tartışma}

\subsection{Bulgular}

Çalışma kapsamında gözlemlerde bulunulan hazır giyim işletmesinde, üretime yeni giren önden bağcıklı, uzun kollu ve ön ortası büzgü detaylı bir bolero modeline ait veriler, siparişin tamamlanma süresi olan 8 gün boyunca kayıt altına alınmıştır. Analiz edilen modelinin üretim operasyonları ve bu operasyonlara dair planlanan ve gerçekleşen zaman verileri Tablo 1'de sunulmuştur. 
Tablo 1. Bolero modelinin operasyonlarına ait üretim verileri

\begin{tabular}{c|l|c|c|c|c}
\hline Sıra & \multicolumn{1}{|c|}{ Operasyon Adı } & $\begin{array}{c}\text { Etüt Süresi } \\
(\mathbf{s n})\end{array}$ & $\begin{array}{c}\text { Gerceklesen } \\
\text { Süre (sn) }\end{array}$ & $\begin{array}{c}\text { En İyi } \\
\text { Süre (sn) }\end{array}$ & $\begin{array}{c}\text { Üretim Verimliliği } \\
(\%)\end{array}$ \\
\hline 1 & Ön Beden Lastik Takma & 10 & 12,6 & 7,6 & 79,37 \\
\hline 2 & Ön Gaze Dikişi & 18 & 19,4 & 15,3 & 92,78 \\
\hline 3 & Ön Beden Sufle & 15 & 21 & 14,5 & 71,43 \\
\hline 4 & Ön K1virma & 33 & 35,8 & 26,1 & 92,18 \\
\hline 5 & Ön Roba Çıma Dikişi & 36 & 41 & 29,3 & 87,80 \\
\hline 6 & Ön Birleştirme & 22 & 40,1 & 24,4 & 54,86 \\
\hline 7 & Çift Omuz Çatma & 12 & 20,8 & 10,6 & 57,69 \\
\hline 8 & Yaka Sufle & 16 & 21,4 & 15 & 74,77 \\
\hline 9 & Firma Etiketi Takma & 10 & 22,8 & 14,3 & 43,86 \\
\hline 10 & Yaka Süs Dikişi & 20 & 20,2 & 14,9 & 99,01 \\
\hline 11 & Kol Ucu Kivırma & 11 & 11,5 & 8,4 & 95,65 \\
\hline 12 & Kol Takma & 25 & 31,5 & 19,9 & 79,37 \\
\hline 13 & Yan Çatma & 38 & 44,7 & 26 & 85,01 \\
\hline 13 & Etek Ucu Kivirma & 12 & 20,3 & 10,4 & 59,11 \\
\hline 15 & Sürfile & 21 & 20,7 & 15,2 & 101,45 \\
\hline 16 & Ön Etek Kırma & 80 & 83,6 & 59,2 & 95,69 \\
\hline 18 & Talimat Takma & 8 & 22,8 & 12 & 35,09 \\
\hline 19 & Kordon Ucu Emniyet Dikişi & 21 & 25,6 & 15,9 & 82,03 \\
\hline 20 & Ütü & 50 & 82,2 & 15 & 60,83 \\
\hline 21 & Son Kalite & 25 & 113 & 0,3 & 22,12 \\
\hline
\end{tabular}

\subsection{Tartışma}

Operasyonlara ait veriler 1şığında, üretim öncesi alınan etüt sürelerinin, gerçekleşen ortalama üretim süresinden özellikle bazı operasyonlarda oldukça farklı olduğu görülmektedir. Toplam üretim boyunca elde edilen en iyi süre verileri incelendiğinde, etüt değerlerine yakın hatta bazılarının bu değerlerden daha düşük olduğu görülmektedir (Şekil 9). Bu verinin, insan işgücü ile gerçekleştirilen bu operasyonlarda, bölücü zamanların yanı sıra kişinin motivasyon durumunun da performansını olumlu ya da olumsuz etkileyebileceğini gösterdiği düşünülmektedir. Yani, online üretim takip sistemlerinde her makinede yer alan ve operatörün kendi verimliliğini gerçek zamanlı görmesini sağlayan panel ekranında, operatörün verimliliğini düşük görmesiyle daha çok çaba gösterip performansını artırmaya çalışmasının, "en iyi süre" değerinin "etüt süresi"nden daha iyi bir sürede elde edilmesine neden olmuş olabileceği düşünülmektedir. Aynı şekilde, üretim verimlilik değerlerinin düşük olmasının nedenleri arasında, model üretim süresinin toplamda 8 gün olması ve bu süre içerisinde modelin banda girişi, operatörlerin operasyonlara alışması ve hatta arada bant dışı yığın oluşan görevlere gönderilmeleri ve yeniden bu modelin bandında üretime dönmelerinden kaynaklanan alışma sürelerinin olduğu düşünülmektedir.

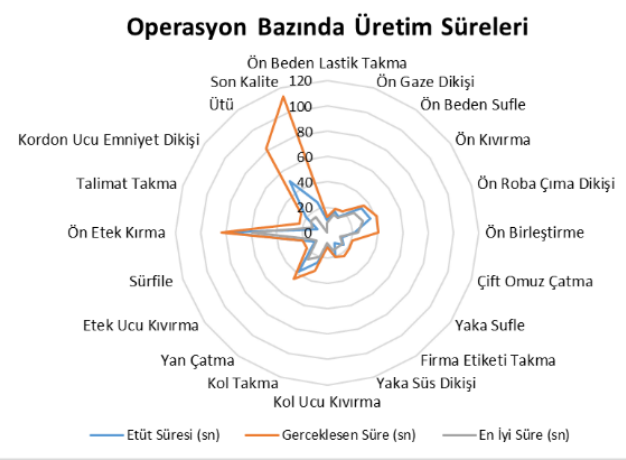

Şekil 9. Tişört modelinin operasyon bazında üretim süreleri
Modelin toplam üretim süresince operasyon bazında günlük verimlilik değerlerine örnek olması açısından "ön gaze dikişi”" operasyonunun verimlilik değerlerine ait grafik Şekil 10’da sunulmuştur. Buna göre modele giriş aşamasında operasyona alışmanın gerçekleştiği ilk gün verimliliğin düşük olduğu görülmektedir.

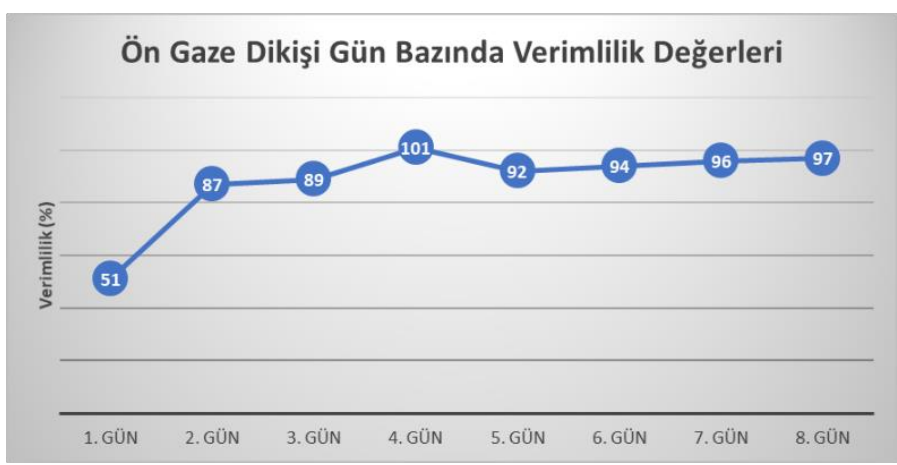

Şekil 10. Ön gaze dikişi operasyonunun günlük verimlilik değerleri

Üretimde oluşan bölücü zamanların gün bazında dağılımı Tablo 2'de verilmiştir. Buna göre, en çok duruşun yaşanmasının operatörlerin lavabo ihtiyacından kaynaklandığ 1 ve bu değerin toplam duruşların \%89'undan fazlasına karşılık geldiği görülmüştür. Elde edilen bu veri değerlendirildiğinde, işletmenin yerleşim planlamasında değişikliğe gidebileceği ve böylece operatörün lavaboya ulaşma süresinin kısaltılabileceği düşünülmektedir. 
Tablo 2. Gün bazında yaşanan duruşların dă̆ılımı (dakika)

\begin{tabular}{c|c|c|c|c|c|c|c}
\hline Tarih & $\begin{array}{c}\text { Hatalı } \\
\text { Çalışma }\end{array}$ & $\begin{array}{c}\text { İğne } \\
\text { Değişim }\end{array}$ & $\begin{array}{c}\text { İş } \\
\text { Tamir }\end{array}$ & Lavabo & Toplantı & Arıza & Toplam \\
\hline 1. gün & 0 & 0 & 0 & 92 & 0 & 0 & 92 \\
\hline 2. gün & 0 & 0 & 0 & 153 & 0 & 4 & 157 \\
\hline 3. gün & 0 & 0 & 0 & 215 & 0 & 0 & 215 \\
\hline 4. gün & 0 & 2 & 0 & 254 & 0 & 0 & 256 \\
\hline 5. gün & 0 & 2 & 0 & 120 & 125 & 0 & 247 \\
\hline 6. gün & 0 & 0 & 0 & 179 & 0 & 0 & 179 \\
\hline 7. gün & 0 & 0 & 0 & 96 & 0 & 0 & 96 \\
\hline 8. gün & 0 & 0 & 0 & 40 & 0 & 0 & 40 \\
\hline
\end{tabular}

Şekil 11'de model bazında günlük genel üretim verimliliği sunulmuştur. Veriler incelendiğinde, modelin banda girdiği ilk gün verimliliğin diğer günlere göre bir miktar düşük olduğu görülmektedir. Operatörlerin modele alışma sürecinden kaynaklandığı düşünülen bu durum, takip eden günlerde değişiklik göstermekte ve verimlilik grafiği artan bir eğimle devam etmektedir. Duruş sürelerinin en yüksek olduğu 4. ve 5. günlerde üretim verimliliğinin olumsuz etkilendiği görülmekte ve verimlilikte yaşanan düşüşün en önemli nedenleri arasında duruş sürelerinin olduğu anlaşılmaktadır.

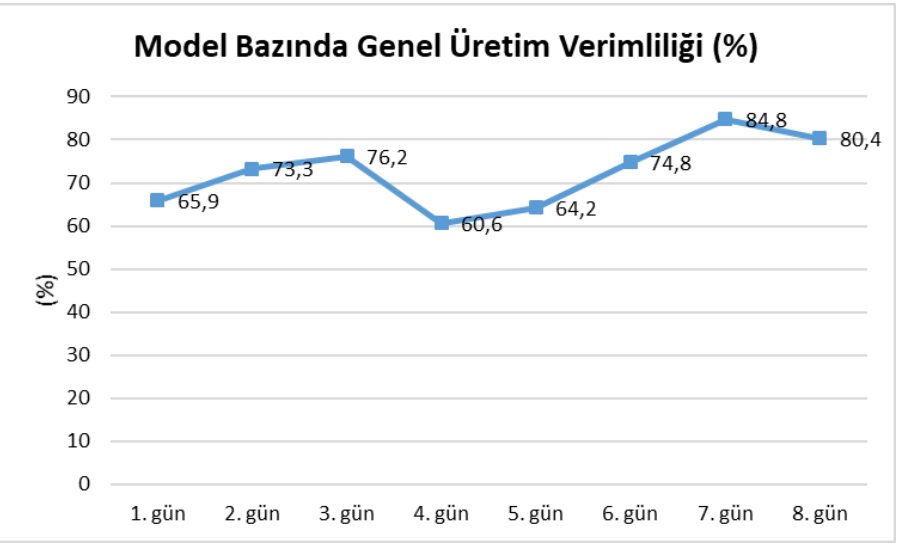

Şekil 11. Model bazında günlük genel üretim verimliliği değerleri

\section{Sonuç ve Öneriler}

Gerçekleştirilen bu çalışma kapsamında Tracetech online üretim takip sisteminin kullanıldığ 1 bir orta ölçekli hazır giyim işletmesinde üretime yeni giren önden bağcıklı, uzun kollu ve ön ortası büzgü detaylı bir bolero modeline ait veriler, siparişin tamamlanma süresi olan 8 gün boyunca kayıt altına alınmıştır. Modele ait verimlilik değerleri operasyon ve model bazında analiz edilmiştir. Duruş sürelerinin de değerlendirilmesiyle, duruşların genel verimlilik üzerindeki etkisi açıkça görülmüştür. Verimliliğin artırılması aşamasında işletmelerin duruşların azaltılması için gerekli tedbirlerin alınması konusuna ağırlıklı olarak önem vermeleri gerektiği sonucuna varılmaktadır.

Mevcut üretim takip sistemlerinde operatörün bir forma yaptığı işleri yazması ya da yaptığı işlere özel olarak hazırlanan etiketleri yapıştırması söz konusuydu. Ancak bu formların daha sonra veri girişi için tekrar işleme alınması gerekmekteydi. Veri girişi ve operatör verimliliğinin hesaplanması için ayrı personel görevlendirilmekteydi. Formların kaybolması, etiketlerin kaybolması, formların doldurulmasında operatörlerin hatalar yapması ve veri girişinde hataların yapılması verimliliğin hesaplanması sırasında dezavantajlar oluşturmaktaydı.

Teknolojinin hızla gelişmesiyle, üretim takibi alanında da ön plana çıkan online üretim takip sistemleri, üretim adetlerinin yanı sıra operasyon, operatör, bant ve genel işletme bazında verimlilik değerlerinin gerçek zamanlı olarak takip edilmesine olanak sağlamaktadır. Böylece, verimi etkileyecek olası aksaklıklar anında görülmekte ve müdahale edilerek verimlilik düşüşü engellenmektedir. Aynı zamanda, bu sistem sayesinde günlük, haftalık, aylık ve yıllık olacak şekilde uzun soluklu kaydedilen verimlilik grafikleri üzerinden analizler yapmak mümkün olmaktadır. Operatörlerin aylık verimlilik verileri genellikle akort primlerinin belirlenmesinde kullanılmaktadır.

\section{Teşekkür}

$\mathrm{Bu}$ çalışmamız sırasında vermiş oldukları desteklerden dolayı EFATECH Tekstil Elk. Mak. San. ve Tic. Ltd. Şti.'ne teşekkür ederiz.

\section{Kaynakça}

[1] Özsever, Ç., Gençoğlu, T. ve Erginel, N. (2009). İşgücü verimlilik takibi için sistem tasarımı ve karar destek modelinin geliştirilmesi. Dumlupınar Üniversitesi fen Bilimleri Dergisi, Sayı.18, ss.45-58.

[2] Kanat, S. ve Güner, M.. (2007). Tekstil ve konfeksiyon işletmelerinde verimlilik ölçümü. Tekstil ve Konfeksiyon, Say1.4, ss.279-283.

[3] Güner, M. ve Yücel, Ö. (2014). Konfeksiyon işletmelerinde verimlilik geliştirici uygulamalar, Tekstil ve Mühendis, Say1.21(95), ss.30-37.

[4] Küçük, M. ve Güner, M., (2015). Bir konfeksiyon işletmesinde süreç analizi yolu ile verimlilik artırma çalışması. Tekstil ve Mühendis, Sayı.22(98), ss.33-41.

[5] Dalğar, H. (2012). İşletmelerde maliyet muhasebesi ile entegre üretim takip sisteminin oluşturulması: bir vaka çalışması. Muhasebe ve Finansman Dergisi, ss.29-50

[6] Tekin, M., Zerenler, M. ve Bilge, A. (2005). Bilişim teknolojileri kullanımının işletme performansına etkileri: 
Lojistik sektöründe bir uygulama. Istanbul Ticaret Üniversitesi Fen Bilimleri Dergisi, Y11.4(8), ss.115-129.

[7] Boorla, S., M. and Howard, T.J. (2016). Production monitoring system for understanding product robustness. Advances in Production Engineering and Management, Vol.11(3), pp.159-172.

[8] Prasad, S., H., C., Rao, P., S., Gopalkrishna, B. and Ahluwalia, A. (2016). Productivity enhancement through production monitoring system. International Journal of Applied Business and Economic Research, Vol.14(3), pp.339-351.

[9] Cwikla, G. (2014). Real-time monitoring station for production systems. Advanced Materials Research, Vol.837, pp.334-339.

[10] Li, T., Qin, W., Zhang, J., Li, H., Xu, Z. and Xiao, H. (2014). Research and Application of Visualized Real-time Monitoring System for Complex Product Manufacturing Process. Key Engineering Materials, Vols.579-580, pp.787791.

[11] Huang, Z., He, Z., Gao, M., Liu, Y. and Lu, D. (2016). The design and research of film capacitor production monitoring system. Proceedings of 2016 IEEE: International Conference on Mechatronics and Automation, pp.18701875.

[12] Cıda, A. ve Sağbaş, A. (2019). RFID Tabanlı Üretim Takip Otomasyonu Sistem Tasarımı ve Uygulaması: Metal Sektörü Saha Çalışması. European Journal of Engineering and Applied Sciences. 2(2), 6-12.

[13] Boz, S. and Arıkan, C.O. (2018). The Smart Fabric Inspection Machines (SFIM). 8th International İstanbul Textile Conference Evolution of Technical Textiles, 14-16 April, İstanbul, Turkey.

[14] Rohman, H. A., Renaldi, F., Umbara, F. R. (2020). Production Monitoring Information System: Managing Supply and Demand in the Textile Factory. 5th NA International Conference on Industrial Engineering and Operations Management, August 10 - 14, Detroit, Michigan, USA.

[15] Sitepu, A. P., Renaldi, F., Ashaury, H. (2021). ComputerBased Multi-Layered Monitoring Systems on Textile Manufacturing Processes. Journal of Physics: Conference Series. $1845 \quad$ (2021) 012023 , doi:10.1088/17426596/1845/1/012023

[16] Trisdiyanti, R., Renaldi, F., Umbara, R. (2020). Implementation of Production Monitoring Systems in A Small Textile Company. 5th NA International Conference on Industrial Engineering and Operations Management, August 10 - 14, Detroit, Michigan, USA.

[17] https://www.efatech.com.tr/tekstil-uretim-izleme-sistemi, Erişim tarihi: 26 Ekim 2021. 